\title{
EFFECTS OF WHOLE-GROUND FLAX SEEDS VERSUS FLAX OIL FOR PESTICIDE RESIDUES-INDUCED NEPHROTOXICITY IN MALE WISTAR RATS
}

\author{
Lubna Shahper ${ }^{1 \otimes}$, Fozia Farzana', Muhammad \\ Qasim Muneer,', Sadia Hassan ${ }^{1,3}$, \\ Romana Hashim ${ }^{1,4}$, Maria llyas ${ }^{1,{ }^{\prime}}$
}

\begin{abstract}
OBJECTIVE: To observe the possible curative effects of whole-ground flax seeds meal versus flax oil for pesticide residue-induced nephrotoxicity.

METHODS: In this experimental study, 24 male Wistar rats were divided into four equal groups: control group $(A)$ and experimental groups (B, C \& D), as approved by ethical committee, Postgraduate Medical Institute, Lahore, Pakistan. Subchronic dose of triazophos $-8.2 \mathrm{mg} / \mathrm{kg}$ body weight $\left(1 / 10^{\text {th }}\right.$ of $\left.L_{50}\right)$ was given to the group $B, C \& D$ via oral gavage, as $1: 100$ dilution solution for 21 consecutive days. In addition, group $C$ was given flax seeds oil ( $1.86 \mathrm{~g} / \mathrm{kg} /$ day $)$ while group D was given whole ground flax seeds meal $(800 \mathrm{mg} / \mathrm{kg} /$ day $)$. Biochemical analysis of serum creatinine on day I, 7, 14 and 21 was done. Hematoxylin and Eosin and Periodic Acid Schiff staining was used for renal histological examination. Mean diameter of renal corpuscle (RCD), proximal convoluted tubule (PCT) and distal convoluted tubule (DCT) in all groups were calculated by micrometry.
\end{abstract}

RESULTS: Micrometric measurement in group A were as follows: RCD$89.43 \pm 3.43 \mu \mathrm{m}, \mathrm{PCT}$ diameter-38.90 $\pm 2.72 \mu \mathrm{m}$, DCT diameter- $34.48 \pm 2.58 \mu \mathrm{m}$. Group B, C \& D slides showed RCD $-70.12 \pm 2.76 \mu \mathrm{m}, 80.67 \pm 3.34 \mu \mathrm{m}$, $87.49 \pm 4.66 \mu \mathrm{m}, P C T$ diameters $(50.35 \pm 2.6 \mathrm{I} \mu \mathrm{m}, 43.70 \pm 2.35 \mu \mathrm{m}$, $38.45 \pm 2.57 \mu \mathrm{m})$ and DCT diameters $(48.03 \pm 3.42 \mu \mathrm{m}, 38.65 \pm 2.55 \mu \mathrm{m}$, $35.33 \pm 3.02 \mu \mathrm{m})$ respectively. Biochemical analysis showed raised serum creatinine in group B $(2.183 \pm 0.367 \mathrm{mg} / \mathrm{dL})$, near normal levels in group C $(0.698 \pm 0.013 \mathrm{mg} / \mathrm{dL})$ \& comparable with control group, in group $D$ $(0.718 \pm 0.05 \mathrm{Img} / \mathrm{dL})$.

CONCLUSION: Renal tissue when exposed to pesticides, showed disturbed biochemical and histological architecture. Whole-ground flax seeds ameliorate the histopathological and biochemical renal damage better than flax seeds oil against pesticides-residues exposure.

KEY WORDS: Insecticides (MeSH); Linum usitatisimum seeds (Non-MeSH); Flax (MeSH); Linseeds (MeSH), Linseeds Oil (MeSH); Renal Damage (MeSH); Whole-ground form (Non-MeSH).

THIS ARTICLE MAY BE CITED AS: Shahper L, Farzana F, Muneer MQ, Hassan S, Hashim R, llyas M. Effects of whole-ground flax seeds versus flax oil for pesticide residues-induced nephrotoxicity in male Wistar rats. Khyber Med Univ J 2020; I 2(2):86-94. DOI: 10.35845/kmuj.2020.19869.

\section{INTRODUCTION}

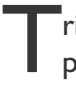
riazophos, an organophosphorus pesticide is used rampantly on crops to ensure that the farmers get the crop yield they demand, no matter how much the nutritional value of the food is compromised and how it hurts the environment or the consumers.' The people who are at risk of exposure are the personnel handling this chemical, their families and the people consuming
I. Department of Anatomy, Post Graduate Medical Institute (PGMI) / Ammer Ud Din Medical College, Lahore, Pakistan.

2 Department of Anatomy, Alama lqbal Medical College, Lahore, Pakistan.

3. Department of Anatomy, Services Institute of Medical Sciences (SIMS), Lahore, Pakistan.

4. Department of Anatomy, Akhtar Saeed Medical College, Lahore, Pakistan.

5. Department of Anatomy, Al-Aleem Medical College, Gulab Devi Educational Complex Lahore, Pakistan. Email『: lubishah@hotmail.com Contact \#: +92-323-4000656

Date Submitted: November 10, 2019 Date Revised: March 03, 2020

Date Accepted: March 07, 2020

fruits and vegetables with pesticide residues. ${ }^{2}$ Kidney and liver are the most affected organs against pesticide toxicity and oxidative damage, as they play key role in the their elimination. ${ }^{3}$

As the trend of the future is moving towards functional food with specific health benefits, flax seeds, a rich source of natural antioxidants in the form of flavonoids ${ }^{4}$, can be used for protection against cellular oxidative damage as they have been proven to protect cells against oxidative stress. ${ }^{5}$ Flax seeds, also called linseeds or ALSI, are full of healthy fat, fiber and antioxidants. The bioactive ingredients of flax seeds include strong antioxidants, omega- 3 short-chain polyunsaturated fatty acidsPUFA/alpha-linolenic acid or ALA (52\%), phenolic lignan component, phytoestrogen SDG (secoisolariciresinol-diglucoside) in the form of a colloid gum which exhibits antioxidant activity by inhibiting lipid peroxidation and also acts as a weak estrogenic compound, proteins (22 $\mathrm{gm} / \mathrm{l} 00 \mathrm{gm}$ of seeds), an array of antioxidants, minerals and soluble/ insoluble fiber (20-25\%). ${ }^{6}$

Comparing flax seeds meal as a whole food and flax seed oil, the former is superior to the latter, when it comes to choosing a food that provides a full package of beneficial nutrients. Whole ground flax meal is a rich source of dietary fiber, polyphenols, minerals and vitamins while oil lacks these essential 
TABLE I: EXPERIMENTAL GROUPS OF ANIMALS

\begin{tabular}{|c|l|c|}
\hline Groups & \multicolumn{1}{|c|}{ Intervention and dosage in $200 \mathrm{~g}$ rat } & Day \\
\hline $\mathrm{A}$ & Normal saline $0.5 \mathrm{ml}$ & $\mathrm{I}-2 \mathrm{I}$ \\
\hline $\mathrm{B}$ & Triazophos dilution solution $0.5 \mathrm{ml}$ at a dose of $8.2 \mathrm{mg} / \mathrm{kg}$ & $\mathrm{I}-2 \mathrm{I}$ \\
\hline \multirow{2}{*}{$\mathrm{C}$} & Triazophos dilution solution $0.5 \mathrm{ml}$ at a dose of $8.2 \mathrm{mg} / \mathrm{kg}$ & \multirow{2}{*}{$\mathrm{I}-2 \mathrm{I}$} \\
\cline { 2 - 3 } & Flax seeds oil, $2 \mathrm{ml}$ at a dose of $\mathrm{I} .86 \mathrm{~g} / \mathrm{kg}$ & \multirow{2}{*}{$\mathrm{I}-2 \mathrm{I}$} \\
\hline \multirow{2}{*}{$\mathrm{D}$} & Triazophos dilution solution $0.5 \mathrm{ml}$ at a dose of $8.2 \mathrm{mg} / \mathrm{kg}$ & \\
\cline { 2 - 3 } & Flax seeds suspension of whole ground meal $-0.6 \mathrm{ml}$ at a dose of $800 \mathrm{mg} / \mathrm{kg}$ & \\
\hline
\end{tabular}

TABLE II: COMPARISON OF INITIAL FINAL BODY WEIGHTS AMONG GROUPS

\begin{tabular}{|l|c|c|c|c|c|}
\hline \multicolumn{1}{|c|}{ Parameters } & Group A & Group B & Group C & Group D & p-value \\
\hline Initial body weight $(\mathrm{g})$ & $188 \pm 8.5$ & $190 \pm 5.1$ & $19 I \pm 4.3$ & $189 \pm 8.6$ & 0.845 \\
\hline Final body weight $(\mathrm{g})$ & $217 \pm 7.4$ & $205 \pm 4.5$ & $231 \pm 3.4$ & $223 \pm 9.3$ & $<0.00 \mathrm{I}$ \\
\hline Percentage gain & $15.7 \pm 2.6$ & $7.9 \pm 1.5$ & $21 \pm 1.4$ & $18.5 \pm 1.05$ & $<0.00 \mathrm{I}$ \\
\hline
\end{tabular}
One way ANOVA: " p value $\leq 0.05$ is considered statisically significant

TABLE III: COMPARISON OF DIAMETER OF RENAL CORPUSCLE, PROXIMAL AND DISTAL CONVOLUTED TUBULES AMONG GROUPS

\begin{tabular}{|l|c|c|c|c|c|}
\hline \multicolumn{1}{|c|}{ Parameters } & Group A & Group B & Group C & Group D & p-value \\
\hline $\begin{array}{l}\text { Renal Corpuscle } \\
\text { Diameter }(\mu \mathrm{m})\end{array}$ & $89.43 \pm 3.43$ & $70.12 \pm 2.76$ & $80.67 \pm 3.34$ & $87.49 \pm 4.66$ & $<0.00$ I $^{*}$ \\
\hline $\begin{array}{l}\text { Proximal Convoluted } \\
\text { Tubule Diameter }(\mu \mathrm{m})\end{array}$ & $38.90 \pm 2.72$ & $50.35 \pm 2.61$ & $43.45 \pm 2.57$ & $39.70 \pm 2.35$ & $<0.00$ I $^{*}$ \\
\hline $\begin{array}{l}\text { Distal Convoluted } \\
\text { Tubule Diameter }(\mu \mathrm{m})\end{array}$ & $34.48 \pm 2.58$ & $45.03 \pm 3.42$ & $40.65 \pm 2.55$ & $35.33 \pm 3.02$ & $<0.00$ I $^{*}$ \\
\hline
\end{tabular}

One way ANOVA; $" p$ value $\leq 0.05$ is considered statistically significant

TABLE IV: PAIR WISE COMPARISON OF RENAL CORPUSCLE DIAMETER AMONG GROUPS

\begin{tabular}{|c|c|c|c|c|}
\hline \multirow{2}{*}{\multicolumn{2}{|c|}{ Group }} & \multicolumn{3}{|c|}{ Renal Corpuscle Diameter $(\mu \mathrm{m})$} \\
\hline & & \multirow{2}{*}{$\begin{array}{c}\text { Mean Difference }(\mu \mathrm{m}) \\
\text { 19.31500* }\end{array}$} & \multirow{2}{*}{$\begin{array}{c}\text { Standard Error } \\
2.08717\end{array}$} & \multirow{2}{*}{$\begin{array}{c}\text { p-value } \\
0.000\end{array}$} \\
\hline \multirow{3}{*}{ A } & B & & & \\
\hline & C & 3.76167 & 2.08717 & 0.301 \\
\hline & $\mathrm{D}$ & 7.94333* & 2.08717 & 0.006 \\
\hline \multirow{2}{*}{ B } & C & $-15.55333 *$ & 2.08717 & 0.000 \\
\hline & $\mathrm{D}$ & $-11.37167 *$ & 2.08717 & 0.000 \\
\hline$C$ & $\mathrm{D}$ & 4.18167 & 2.08717 & 0.220 \\
\hline
\end{tabular}

Post hoc Tukey; ${ }^{p}$ value $\leq 0.05$ is considered statistically significant

nutrients. ${ }^{4}$

The oxidative stress produced in the human body by pesticide-residueintake through fruits, vegetables, rice, milk, grains and contaminated water produces oxidative damage due to overproduction of reactive oxygen species or insufficiency of cellular antioxidative systems leads to renal tissue oxidative damage and inhibits the normal cellular functions.' This damage can be prevented by intake of exogenous antioxidants in diet and ground flax seeds is an excellent choice preventing renal oxidative damage due to pesticides residues. ${ }^{6}$

Flax oil is commercially available to be used as an antioxidant agent for various diseases but due to high price, it is not within the reach of a common man. Fortunately, it can be eaten in different forms of consumption as new technologies have allowed to separate different parts of flax seeds to obtain specific benefits. ${ }^{6}$ They can be eaten as whole or oil can be extracted from the seeds. Whole flax seeds must be ground for getting these antioxidants, thus or milled before consumption in order to reap all the assorted health benefits, as whole flax seeds are very hard and can pass through the body undigested if their outer capsule is intact. Grinding increases their digestibility. ${ }^{4}$ The oil extracted from the seeds is also used as a strong antioxidant agent, but flax seed oil does not provide all the ingredients of flax seeds. ${ }^{7}$

Flax seeds can also be used as partially or completely dehulled form but are not equal to the total nutrient package when these seeds are ground as a whole as the decreased hull (outer hard capsule) content only decreases the extremely beneficial fiber and lignan content. ${ }^{6}$ Other forms or products/fractions include fully defatted flax seeds meal, partially defatted flax seed meal, flax seed mucilage extracts, flax seed hulls, flax seed oleosomes and flax seed alcohol extracts. Each of these products contains more than one bioactive component and are associated with specific health benefit but the presence of plurality of bioactive components in flax seed fractions, is commonly ignored. $^{8}$ In order to reap all the beneficial micronutrients, it is better to use ground flax seeds as whole than using in individual forms.

Ground flax seeds have high content of polyphenols or phytonutrients i.e. lignans, having a molecular structure similar to that of human estrogen which help regulate estrogen signaling in the body and act as hormone-balancing, renal and cardio-vascular benefits. When extracting oil from the flax seeds, the lignans get separated from the fats so only ground flax seeds intake can boost up the lignan intake. ${ }^{10}$

Ground flax seeds are easy to keep and use while flax oil must be kept in opaque bottles and cannot be used in cooking since it is far too easily oxidized due to light exposure and heat." It can rather be used by adding to the cooked foods. ${ }^{12}$

The rationale of present study aimed at utilizing the easily available and inexpensive ground flax seeds instead of high-priced flax oil, for the imminent nephrotoxicity produced by the eating pesticide-residues-laden fruits and vegetables. The main objective of 
present study was to observe the possible curative effects of wholeground flax seeds meal versus flax oil for pesticide residue-induced nephrotoxicity.

\section{METHODS}

This experimental study was conducted in 2018, at Post Graduate Medical Institute (PGMI), Lahore, Pakistan after approval from institutional ethical committee. A total of 24 male, Wistar rats were divided into four equal groups, control group $A$ and experimental group $B, C$ \& D (Table I), excluding the sick, ailing and female rats. Rats were purchased from University of Health Sciences, Lahore and kept in the animal house facility of PGMI, Lahore in specialized iron cages. Room temperature was set at $25 \pm 2^{\circ} \mathrm{C}$ and hygienic environment was maintained. They were provided free access to rat chow and water and one week was provided to them for acclimatization.

Sub chronic dose of triazophos-8.2 $\mathrm{mg} / \mathrm{kg}$ body weight $\left(1 / 10^{\text {th }} \text { of } L_{50}\right)^{13}$, a commonly used pesticide was given to the group $B, C \& D$ as dilution solution through oral gavage, while same quantity of distilled water was given to the group $\mathrm{A}$ for $2 \mathrm{I}$ consecutive days. In addition, group $\mathrm{C}$ was given flax seeds oil $(1.86 \mathrm{~g} / \mathrm{kg} / \text { day })^{14}$ while group $D$ was given whole ground flax seeds meal ( 800 $\mathrm{mg} / \mathrm{kg} /$ day $).^{15}$ The doses of the pharmaceutical agents used, were adjusted according to animal weight.

Tail blood was drawn for biochemical analysis of serum creatinine on day I, 7 , 14 and 21 . Blood was coagulated at room temperature for $10-20 \mathrm{~min}$. Samples were centrifuged for 20 minutes at room temperature at a speed of 2000-3000 revolutions per minute. Serum was then separated and stored at $-20^{\circ} \mathrm{C}$. Serum creatinine was measured by Jaffe method using HUMAN Diagnostics (Germany) kit by MicroLab 300 (Netherland).

On day $22^{\text {nd }}$, the rats were sacrificed, and their kidneys dissected out and preserved in 10\% NBF (Neutral buffered formalin) for histological examination. Hematoxylin and Eosin $(\mathrm{H}$ \& E) $)^{16}$ and Periodic Acid Schiff (PAS) ${ }^{17}$ staining was used for histological examination of slides. The mean diameter of renal corpuscle (RCD), proximal convoluted tubule (PCT) and distal convoluted tubule (DCT) in all groups were calculated by micrometry. One-way ANOVA test was applied to compare the diameters using SPSS version 21.0 .

\section{RESULTS}

The mean body weights of the study animals before the start of the experiment and at the experiment end are shown in Table II. There is an increase in the study animals weights in each group. The percent weight gain ranges from minimum of $7.9 \pm 1.5$ in group B to maximum of $21 \pm 1.4$ in group C (Table II).

TABLE V: PAIR WISE COMPARISON OF PROXIMAL CONVOLUTED TUBULE DIAMETER AMONG GROUPS

\begin{tabular}{|c|c|c|c|c|}
\hline \multicolumn{2}{|c|}{ Groups } & \multicolumn{3}{c|}{ Proximal Convoluted Tubule Diameter $(\mu \mathrm{m})$} \\
\cline { 3 - 5 } \multicolumn{2}{|c|}{} & Mean Difference $(\mu \mathrm{m})$ & Standard Error & p-value \\
\hline \multirow{3}{*}{ A } & B & $-11.4500 *$ & 1.4809 & 0.000 \\
\cline { 2 - 5 } & C & 0.4500 & 1.4809 & 0.990 \\
\cline { 2 - 5 } & D & -1.8000 & 1.4809 & 0.625 \\
\hline \multirow{2}{*}{ B } & C & $11.9000^{*}$ & 1.4809 & 0.000 \\
\cline { 2 - 5 } & D & $9.6500^{*}$ & 1.4809 & 0.000 \\
\hline C & D & -2.2500 & 1.4809 & 0.445 \\
\hline
\end{tabular}

Post hoc Tukey; * ${ }^{p}$ value $\leq 0.05$ is considered statistically significant

TABLE VI: PAIR WISE COMPARISON OF DISTAL CONVOLUTED TUBULE DIAMETER AMONG GROUPS

\begin{tabular}{|c|c|c|c|c|}
\hline \multicolumn{2}{|c|}{ Groups } & \multicolumn{3}{c|}{ Distal Convoluted Tubule Diameter $(\mu \mathrm{m})$} \\
\cline { 3 - 5 } \multicolumn{2}{|c|}{} & Mean Difference $(\mu \mathrm{m})$ & Standard Error & p-value \\
\hline \multirow{3}{*}{ A } & B & $-13.5500^{*}$ & 1.682 & 0.000 \\
\cline { 2 - 5 } & C & -1.1667 & 1.682 & 0.898 \\
\cline { 2 - 5 } & D & -0.8500 & 1.682 & 0.957 \\
\hline \multirow{2}{*}{ B } & C & $12.3833^{*}$ & 1.682 & 0.000 \\
\cline { 2 - 5 } & D & $12.7000^{*}$ & 1.682 & 0.000 \\
\hline C & D & 0.3167 & 1.682 & 0.998 \\
\hline
\end{tabular}

Post hoc Tukey; ${ }^{p}$ value $\leq 0.05$ is considered statistically significan

TABLE VII: COMPARISON OF SERUM CREATININE LEVELS AMONG GROUPS

\begin{tabular}{|c|c|c|c|c|c|}
\hline \multirow{2}{*}{$\begin{array}{c}\text { Day of } \\
\text { measurement }\end{array}$} & \multicolumn{5}{|c|}{ Serum Creatinine (mg/dl) } \\
\hline & Group A & Group B & Group C & Group D & p-value \\
\hline Day I & $0.676 \pm 0.036$ & $0.660 \pm 0.035$ & $0.680 \pm 0.022$ & $0.660 \pm 0.035$ & 0.601 \\
\hline Day 7 & $0.655 \pm 0.039$ & $1.170 \pm 0.242$ & $0.688 \pm 0.039$ & $0.680 \pm 0.032$ & $<0.00 I^{*}$ \\
\hline Day 14 & $0.696 \pm 0.042$ & $1.795 \pm 0.180$ & $0.706 \pm 0.036$ & $0.693 \pm 0.031$ & $<0.00$ I $^{*}$ \\
\hline Day 21 & $0.710 \pm 0.035$ & $2.183 \pm 0.367$ & $0.698 \pm 0.013$ & $0.7|8 \pm 0.05|$ & $<\left.0.00\right|^{*}$ \\
\hline
\end{tabular}

Micrometric measurement in group $\mathrm{A}$ were as follows: RCD $89.43 \pm 3.43 \mu \mathrm{m}$, diameter-38.90 $2.72 \mu \mathrm{m}$, DCT $\& D$ slides showed $R C D-70.12+2.76$ $\mu \mathrm{m}, 80.67 \pm 3.34 \mu \mathrm{m}, 87.49 \pm 4.66 \mu \mathrm{m})$, PCT diameters $(50.35 \pm 2.6 \mathrm{I} \mu \mathrm{m}$, $43.70 \pm 2.35 \mu \mathrm{m}, 38.45 \pm 2.57 \mu \mathrm{m})$ and diameters $(48.03 \pm 3.42 \mu \mathrm{m}$, (3.65 $\pm 2.55 \mu \mathrm{m}, 35.33 \pm 3.02 \mu \mathrm{m})$, with brush border loss in group $B$.

Regarding the diameter of renal corpuscle the difference between (Table III; Figure ) was statistically significant ( $p$-value post hoc Tukey test was applied and showed that renal corpuscles in group $B$ had decreased diameters and this difference among groups $A, B, C$ \& $D$ 


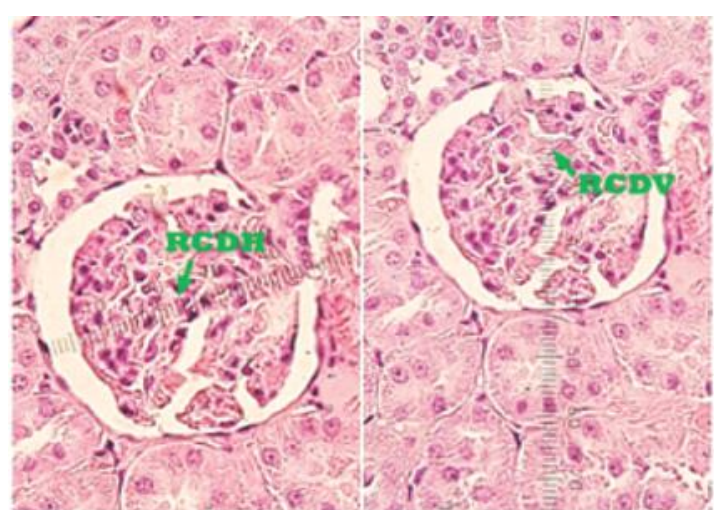

Figure I: Photomicrograph showing the horizontal $(\mathrm{RCDH})$ and vertical (RCDV) renal corpuscular diameter through micrometer. H\&E $\times 400$

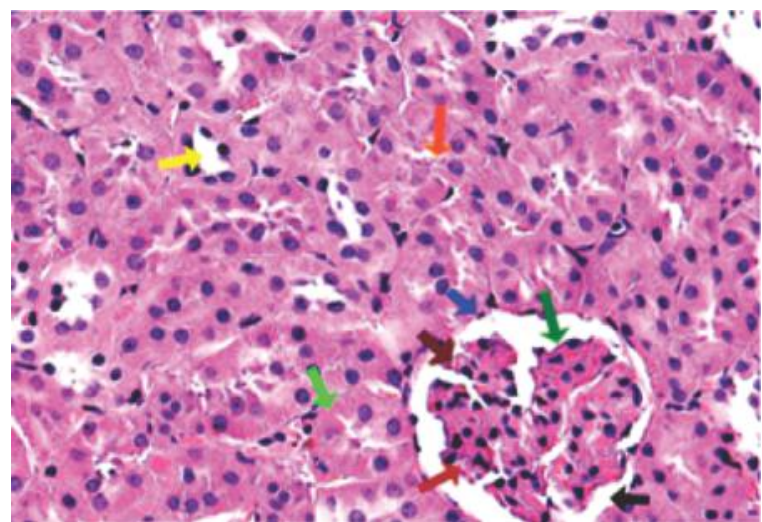

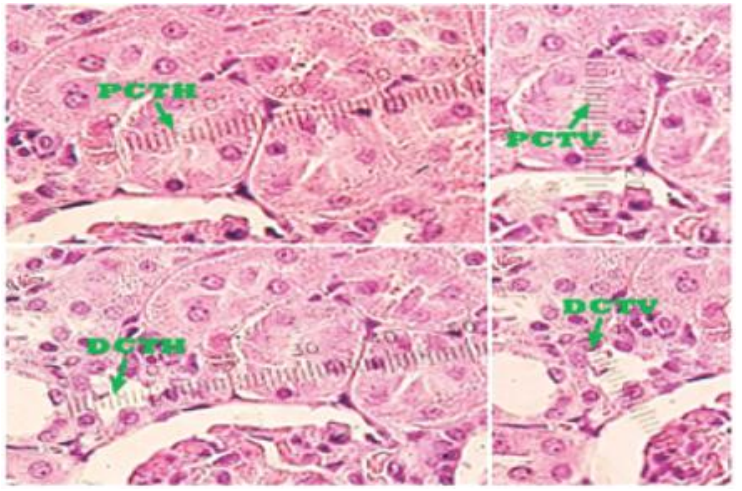

Figure 2: Photomicrograph showing the horizontal and vertical proximal convoluted tubular diameter (PCTH/PCTV) and distal convoluted tubular diameter (DCTH/DCTV) through micrometer. H\&E $\times 400$

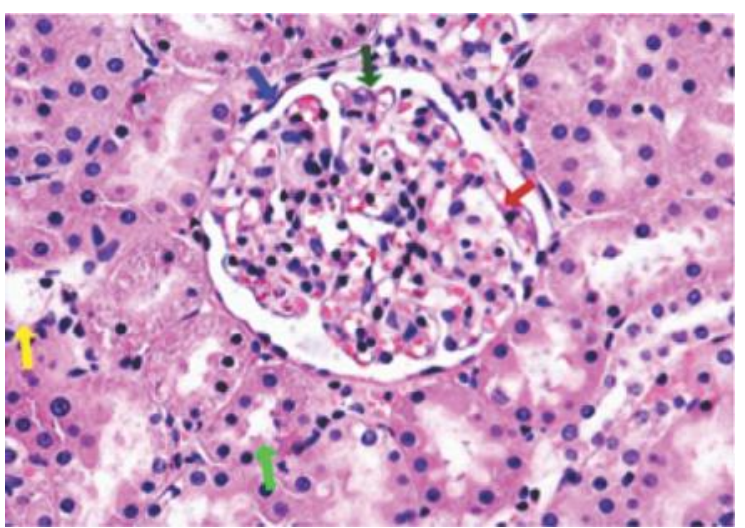

Figure 3: Photomicrograph of Cortex of kidney from group A (i, ii) showing glomerulus (red), parietal layer (blue) and visceral layer (dark-green) of Bowman's space (black), glomerular capillaries (maroon), proximal (light-green) with brush border (orange) and distal (yellow) convoluted tubules. Difference in control group A (Figure 6-ii) and experimental group B (Fig 8-ii) is clearly visible with regard to vascular congestion, vacuolization and interstitial hemorrhages. $\mathrm{H} \& \mathrm{E} \times 400$
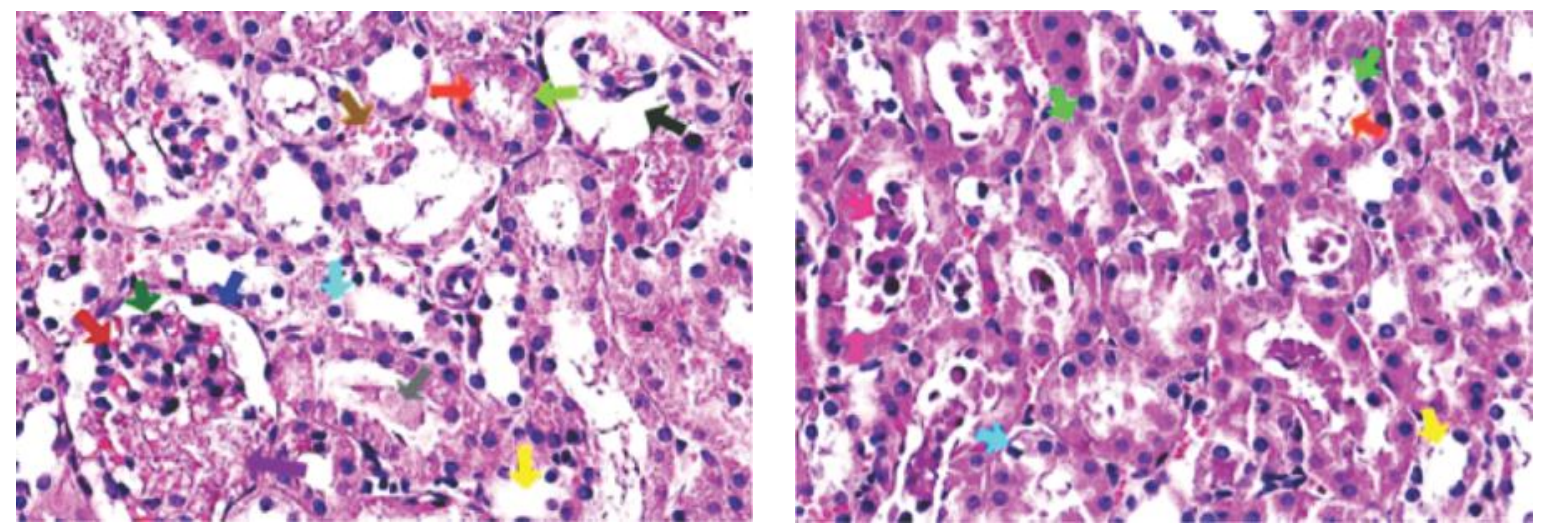

Figure 4: Photomicrograph of group B kidney cortex (i, ii) showing glomerulus (red), enclosed in parietal (blue) and visceral layers (dark-green) of apparently widened Bowman's space (black). Glomerular necrotic changes (purple), degenerative necrotic tubules with desquamating cells (pink) distal tubules (yellow), proximal tubules (light-green), loss of brush border (orange), vascular congestion (brown), protein casts (grey) and vacuoles (aqua blue). H\&E stain $\times 400$.

was statistically significant (Table IV).

One way ANOVA test was applied to compare the diameter of PCT among groups. The difference between group $B$ and other groups was statistically significant ( $\mathrm{p}$-value $<0.00 \mathrm{I}$ ) (Table III;
Figure 2). For multiple comparisons post hoc Tukey test showed that diameter of PCT in group B was 

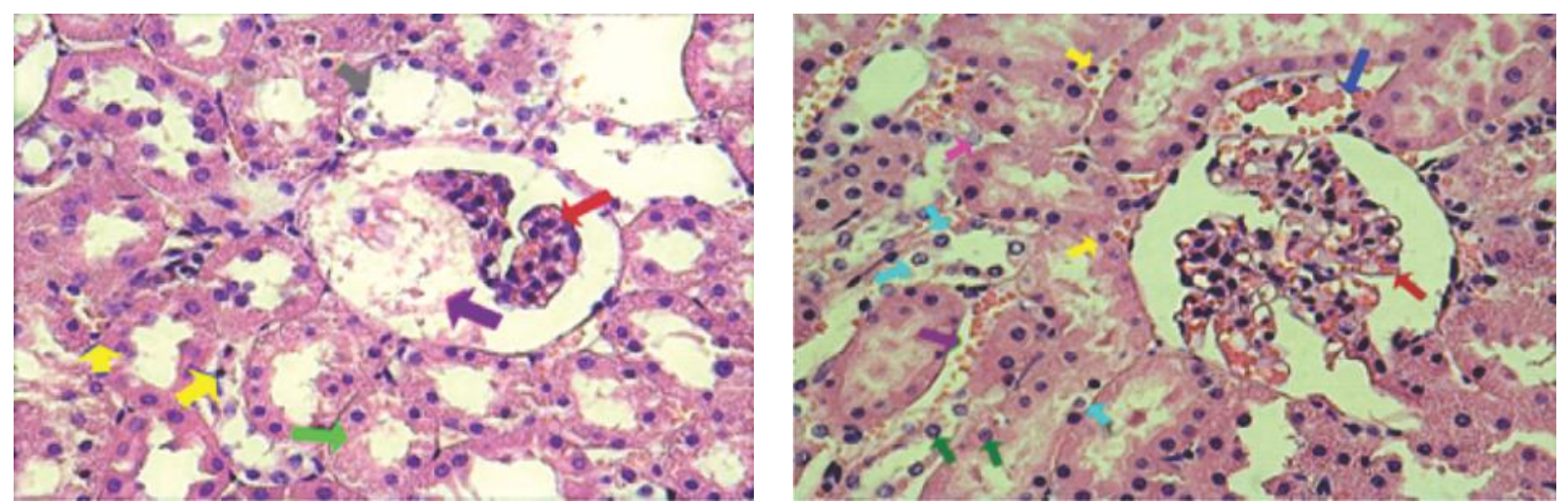

Figure 5: Photomicrograph of cortex of kidney from group B (i, ii) showing glomerulus (red) with necrotic changes (purple), pyknotic nuclei (yellow), karyorrhexis (green), karyolysis(pink), interstitial hemorrhages (orange), cytoplasmic vacuoles (aqua-blue) and vascular congestion (brown) in periglomerular blood vessels, distal (grey) and proximal tubules (light-green). H\&E stain $\times 400$
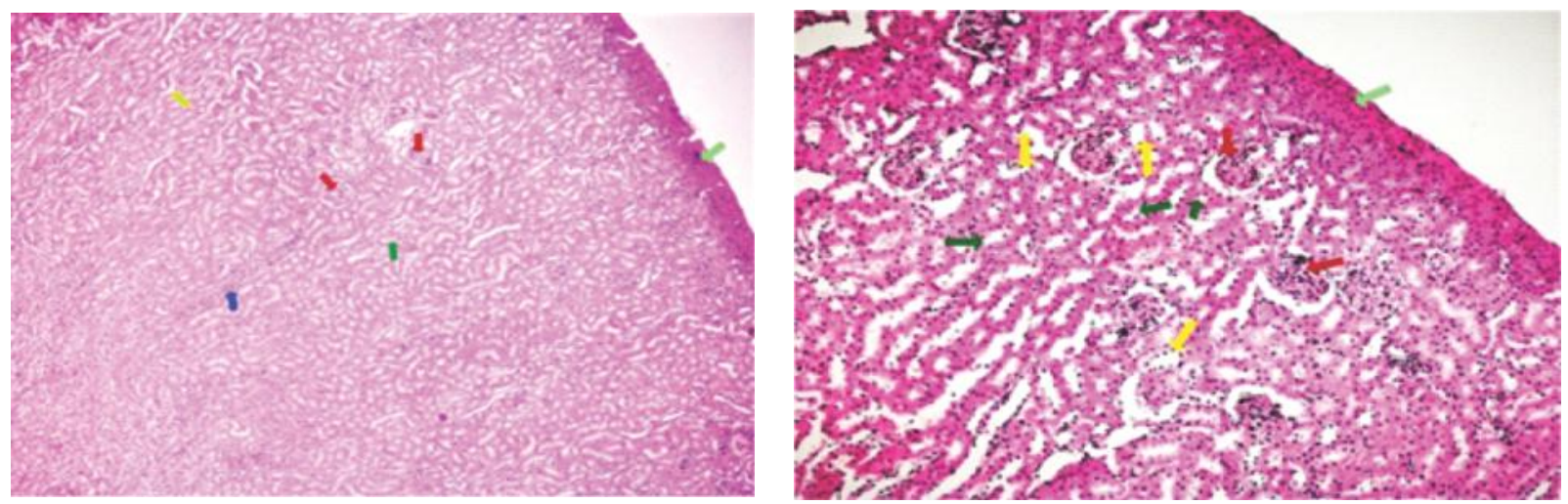

Figure 6: Photomicrograph of group B kidney cortex (i, ii) showing glomerulus (red), marked edema (light green), inflammatory cells collection (blue), proximal (green) and distal (yellow) tubules. H\&E $\times 100 / \times 200$
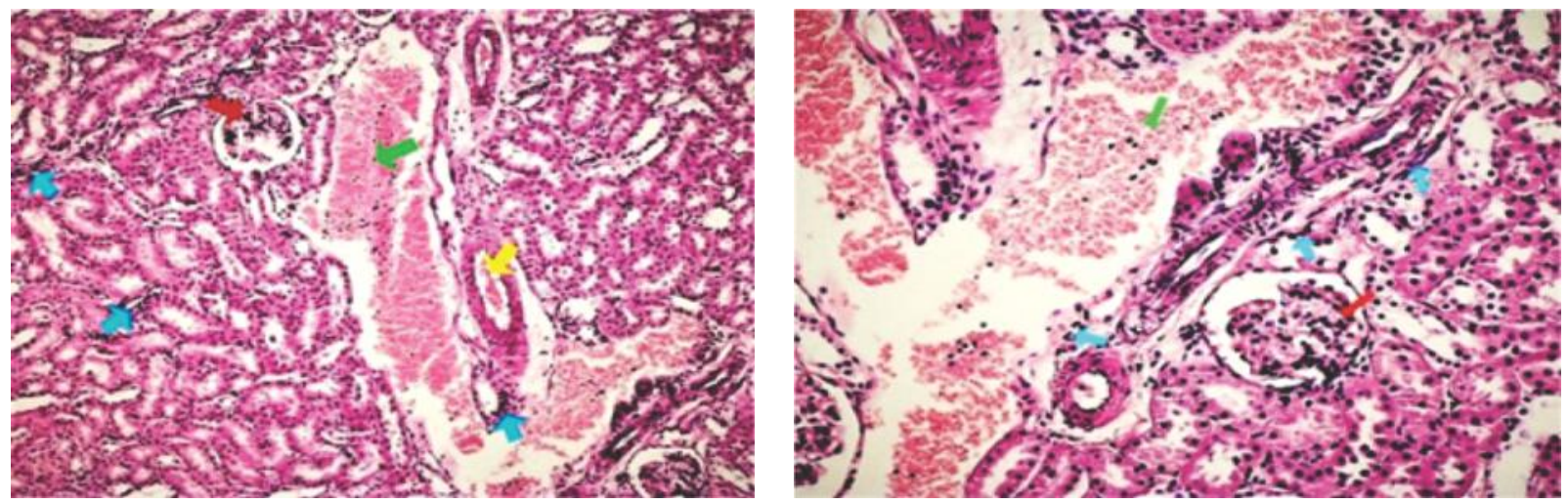

Figure 7: Photomicrograph of group B kidney cortex (i, ii) showing glomerulus (red), vascular congestion (yellow) leading to interstitial hemorrhage (light green) and inflammatory cells (aqua blue). Figure (I0-ii) is higher magnification of Figure (I0-i). H\&E $\times 200 / \times 400$.

statistically significant as compared to group A, C and D. (TableV).

One way ANOVA test was applied to compare the diameter of DCT among groups and It was statistically significant (p-value < 0.00I) (Table III; Figure 2). For multiple comparisons, post hoc Tukey test was applied and it showed that diameter of DCT in group B was statistically significant as compared to group A, C and D. However, no significant difference was found in the diameter of DCT among remaining groups $\mathrm{A}, \mathrm{C}$ and $\mathrm{D}$ (Table VI).

The mean serum creatinine $\mathrm{mg} / \mathrm{dl}$ in all 

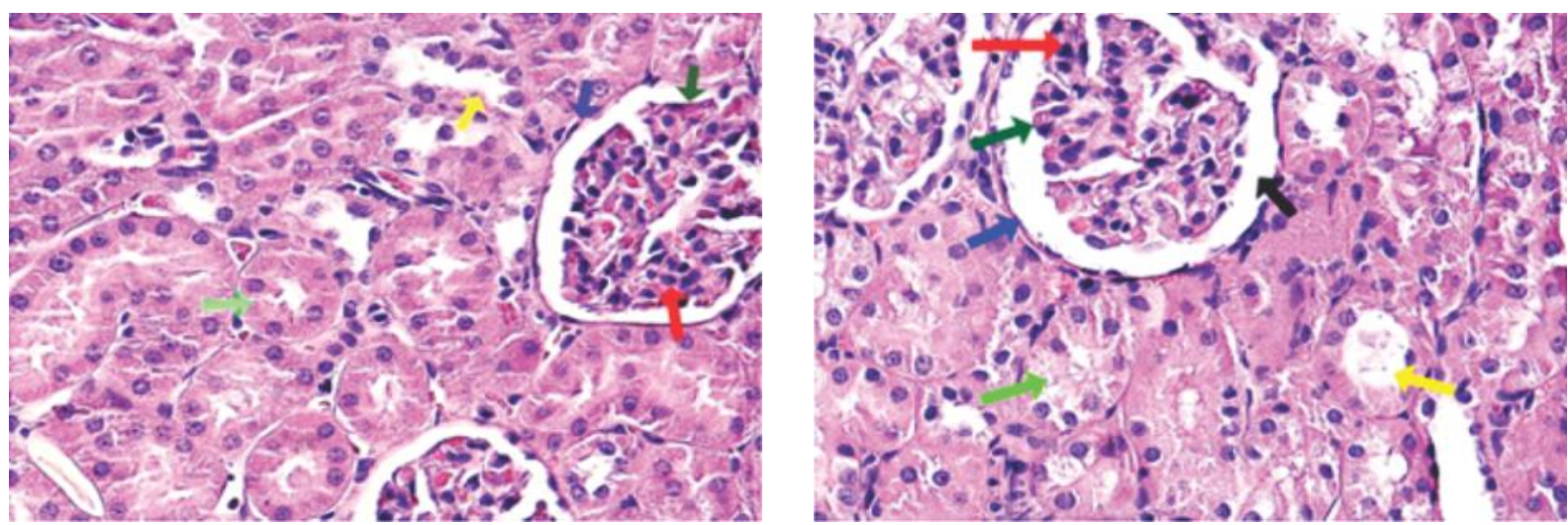

Figure 8: Photomicrograph of kidney cortex group $C$ and $D$ showing glomerulus (red) surrounded by parietal (blue) and visceral (dark-green) layers of Bowman's space (black), proximal tubule (light-green) and distal tubules (yellow). H\&E stain $\times 400$.
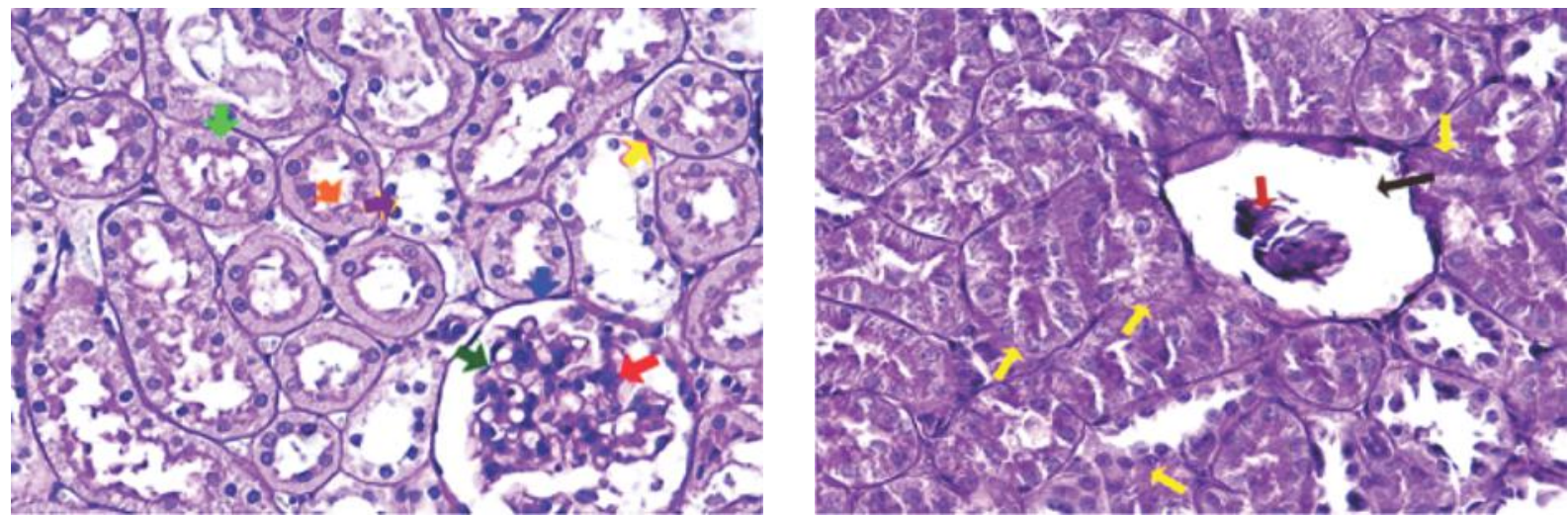

Figure 9: Photomicrograph of group A and B kidney cortex(i, ii) showing glomerulus (red) surrounded by parietal (blue) and visceral layer (dark-green) of Bowman's space (black); proximal tubule (light-green); brush border (orange); distal tubules (purple);

basement membranes (yellow) are strongly PAS positive and intact in control group A while disrupted in group B. PAS stain $\times 400$
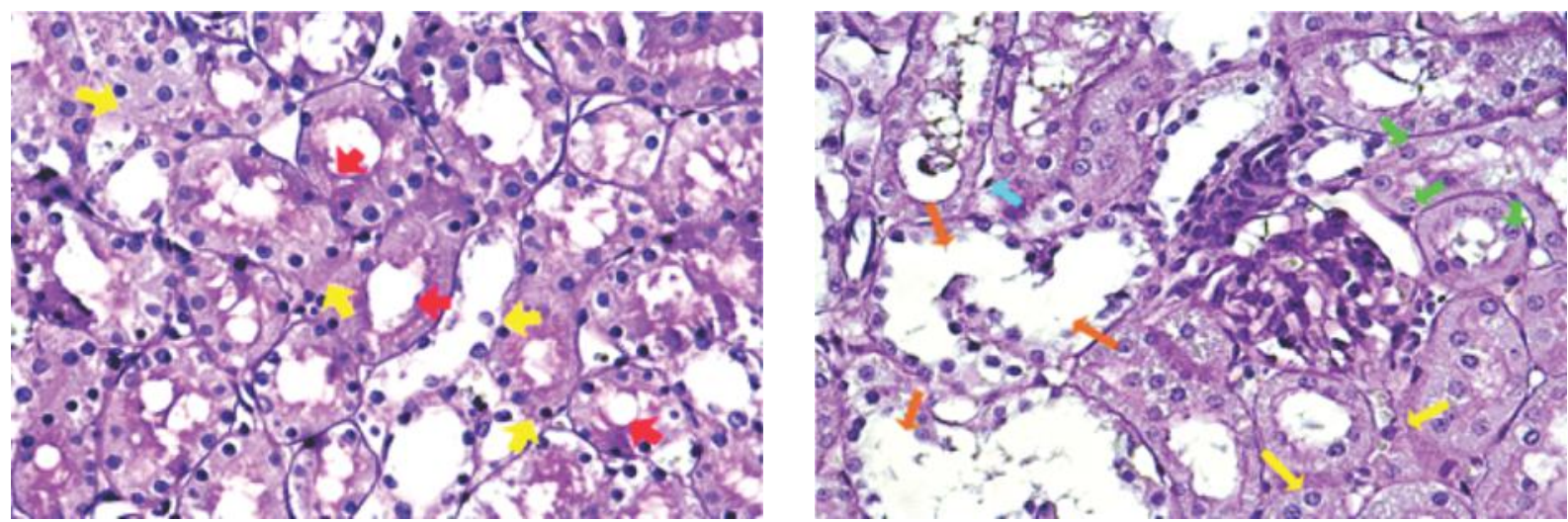

Figure 10: Photomicrograph of group B kidney cortex (i, ii) showing disruption of tubular basement membranes (yellow); loss of brush border (red); disrupting and desquamating tubules (orange); pyknotic nuclei (aqua-blue) and karyorrhexis (light-green). PAS stain $\times 400$ 

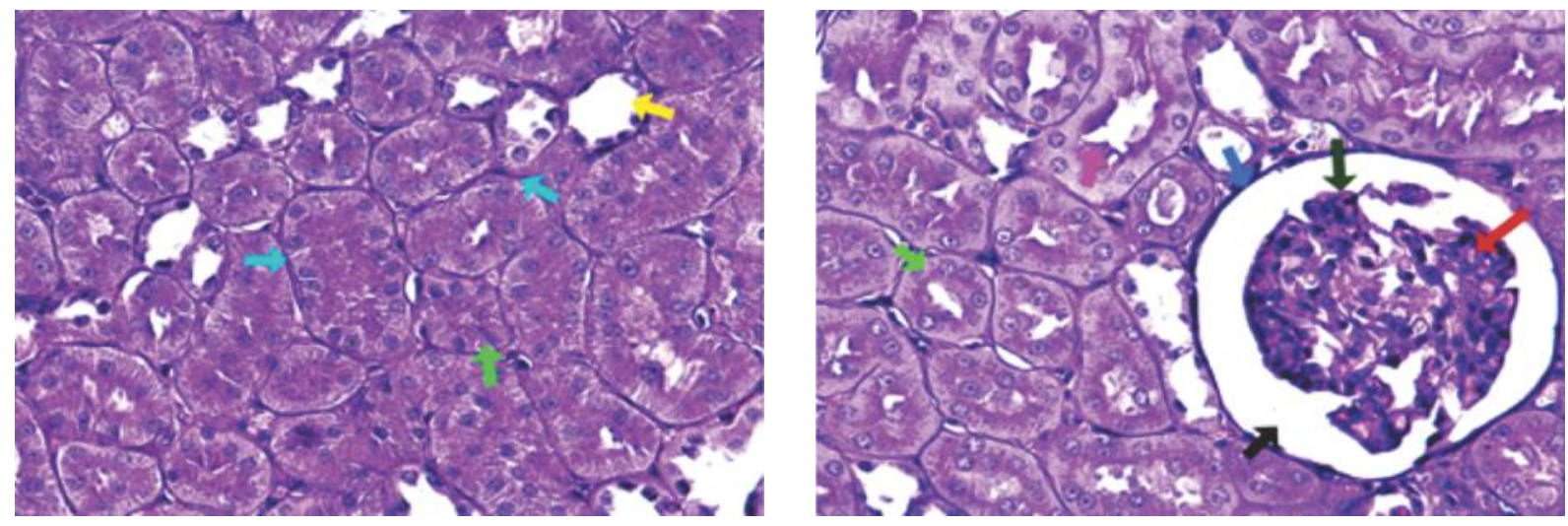

Figure II: Photomicrograph of cortex of kidney from group $C$ and D (i, ii) showing glomerulus (red) surrounded by parietal (blue) and visceral layer (dark-green) of Bowman's space (black); proximal (light green arrow) and distal convoluted tubules (yellow arrow) with intact basement membranes (light-blue arrow). PAS stain $\times 400$

groups was taken at day I, 7, 14 and 21 . Biochemical analysis of serum showed raised serum creatinine levels in group $B$ $(2.183 \pm 0.367 \mathrm{mg} / \mathrm{dL})$, near normal levels in group $\mathrm{C}(0.698 \pm 0.013 \mathrm{mg} / \mathrm{dL})$ \& comparable with control group, in group D $(0.718 \pm 0.051 \mathrm{mg} / \mathrm{dL})$. One way ANOVA test was applied to compare the mean serum creatinine $\mathrm{mg} / \mathrm{dl}$ among groups at day I, 7, I4 and 21 . It was found that the mean serum creatinine $\mathrm{mg} / \mathrm{dl}$ level was not significantly different among the groups at day I $(p$-value $=0.60 \mathrm{I})$. The mean serum creatinine $\mathrm{mg} / \mathrm{dl}$ level was statistically significant among the groups at day 7, I 4 and 2 I (Table VII).

\section{DISCUSSION}

In the $\mathrm{H}$ \& $\mathrm{E}$ stained slides of group $\mathrm{B}$, most of the glomeruli showed dilatation of Bowman's space with glomerular atrophy and necrotic changes due to shrinkage of glomerular tuft capillaries leading to reduced renal corpuscular diameter (Figure 4, 5) as compared with group A (Figure 3). This was observed especially in group B (Table III; Figure 4, 5) where renal corpuscular size was reduced from $89.43 \pm 3.43 \mu \mathrm{m}$ in group A to $70.12 \pm 2.76 \mu \mathrm{m}$ in group $B$ as was also observed by Sharma and Sangha in a similar study on triazophos in $2014 .^{18}$ Group $C$ slides showed curative effects of flax oil by reducing the histopathological effects (Figure 8). However, no significant difference was found in the diameter of renal corpuscle among groups $A$ versus group $D$ (Table
IV; Figure 8) which showed that ground flax seeds meal treated group showed no disturbance in histological architecture, retained the normal renal corpuscular size and ameliorated the histological disturbance created by triazophos.

The diameters of PCT and DCT showed an increase in triazophos treated groups (Table III). The micrometric measurement of diameters of PCT/DCT in group B indicated that they increased significantly ( $p$-value $<0.001$ ) as compared with the control group $A$ as was observed in 2018 by Rahman and Sattar in a study on effects of different doses of pesticides given to mice. ${ }^{19}$ In our investigation, loss of brush border (Figure 9, 10), as was also observed by Sharma and Sangha in a similar study on triazophos in 2014. ${ }^{18}$ In groups $C$ and D, most of the rats had normal brush border (Figure $\mathrm{II}$ ), indicating the attenuation of histological structure due to flax seeds protection against oxidative stress which was also evidenced by Skorkowska-Telichowska $\mathrm{K}$, et al. in 2016 in a study about the protective role of flax seeds emulsion in oxidative stress. ${ }^{5}$ There was severe vacuolar cellular degeneration of tubules as was also observed by Sharma and Sangha in a similar study on triazophos in $2014^{18}$ and interstitial inflammatory cell infiltrate as evidenced in a study on ameliorative effects of flax seeds on interstitial nephritis ${ }^{20}$ (Figure $6,7)$.
In group $B$ and $C$, there were interrupted basement membranes (Figure 9, 10). Basement membranes in rats of group $A$ and $D$ were intact.

Pesticides induce a state of oxidative stress in the cells and generation of reactive oxygen species (ROS) which accumulates in the mitochondria causing structural and functional alterations like mitochondrial swelling, inhibition of mitochondrial respiratory functions, energy (ATP) production and consequently, impaired cellular energydependent processes. ${ }^{21}$

ROS also leads to lipids peroxidation which damages the basement membranes, elevating serum markers of lipid peroxidation levels like catalase, GSH (Glutathione peroxidase) and SOD (superoxide dismutase). ${ }^{22}$ Oxidative stress may induce membrane bleb formation and DNA degeneration and vacuolization, resulting in the breakdown of organelles and finally apoptosis and cellular death. ${ }^{23}$

The mean serum creatinine $(\mathrm{mg} / \mathrm{dl})$ levels were significantly different among the groups at day 7,14 and 21 (Table VII). The imbalance in the kidney function leads to raised serum creatinine as was proved by Rahman and Sattar in 2017. ${ }^{19}$ Raised creatinine levels show deterioration of renal functions suggesting tubular insufficiency and impaired glomerular function.

In the whole-ground flax seed-treated group compared with the flax seed oil- 
treated group, it was proved that the former worked better in protecting and reversing the histopathological changes produced by triazophos-residue toxicity and oxidative damage. Wholeground flax seeds exceeds far more than the flax oil as proved earlier by Shim et al in 2014 in a study on bioactive ingredients of flax seeds. ${ }^{6}$

The limitations of the present study were that the ground flax seeds were not used before or available from the local market so had to be grinded.

\section{CONCLUSION}

The results of experimental group B show markedly decreased glomerular diameter and increased PCT/DCT diameters due to pesticide exposure, as compared with control. This diametric change was also seen in group $C$ and $D$ but with histopathological amelioration by flax seeds. When flax seeds amelioration was compared among group $C$ and D; group D was closely compared with the control group thus proving that easily available and inexpensive, whole-ground flax seeds form better ameliorate the histopathological renal damage than expensive and not so easily available, flax seeds oil against involuntary pesticides-residues exposure.

\section{REFERENCES}

I. Damalas CA, Eleftherohorinos IG. Pesticide exposure, safety issues, and risk assessment indicators. Int J Environ Res Public Health 201I May;8(5): |402-19. DOI: 10. 3390/ijerph805I 402.

2. Syed JH, Alamdar A, Mohammad A, Ahad K, Shabir Z, Ahmed H, et al. Pesticide residues in fruits and vegetables from Pakistan: a review of the occurrence and associated human health risks. Environ Sci Pollut Res Int 2014;2I(23): I336793. DOI: 10.1007 /s I|356-0I43।17-z.

3. Bock R, Thier W. Metabolism and fate of triazophos in rats. Pestic Sci 1 976;7(3):307-|4. DOI: 10.1002/ps. 2780070316.

4. Bernacchia R, Preti R, Vinci G.
Chemical composition and health benefits of flax seeds. Austin J Nutri Food Sci 20 I 4;2(8): 1045.

5. Skorkowska-Telichowska K, Hasiewicz-Derkacz K, G barowski T, Kulma A, Moreira H, Kostyn K, et al. Emulsions made of oils from seeds of GM flax protect V79 cells against oxidative stress. Oxid Med Cell Longev 2016;2016:7510759. DOI: I0.1 I55/2016/75 I0759.

6. Shim YY, Gui B, Arnison PG, Wang Y, Reaney MJ. Flax seeds (Linum usitatissimum L.) bioactive compounds and peptide nomenclature: A review. Trends Food Sci Tech 20I4; 38(I):5-20. DOI: 10.10I6/j.tifs.2014.03.0I I

7. Aryee ANA, Boye JI. Current and emerging trends in the formulation and manufacture of nutraceuticals and functional food products. In: Boye JI (eds), Nutraceutical and Functional Food Processing Technology. 2015, ppl-52. John Wiley \& Sons, Canada. DOI: |0. |002/978| | |8504956.chl.

8. Austria JA, Richard MN, Chahine $M N$, Edel AL, Malcolmson LJ, Dupasquier CM, et al. Bioavailability of alpha-linolenic acid in subjects after ingestion of three different forms of flax seeds. J Am Coll Nutr 2008 Apr I;27(2):2I4-2I. DOI: I 0.1080/ $073 \mid 5724.2008$. 10719693.

9. Goyal A, Sharma V, Upadhyay N, Gill S, Sihag M. Flax and flax seeds oil: an ancient medicine \& modern functional food. J Food Sci Technol 2014 Sep I;5I(9):I633-53. DOI: 10.1007/s |3197-0|3-1247-9.

10. Touré A, Xueming $X$. Flax seeds lignans: source, biosynthesis, metabolism, antioxidant activity, bio active components, and health benefits. Comp R Food Sci Food Saf 2010 May; 9(3):26I-9. DOI:I0. IIII/j.154I-4337.2009.00I05.x.

II. Teh SS, Birch J. Physicochemical and quality characteristics of coldpressed hemp, flax and canola seed oils. J Food Comp Anal 2013 May I; 30(I):26-3I. DOI: I0.1016/ j.jfca.20I 3.01 .004 .
12. Hyvärinen HK, Pihlava JM, Hiidenhovi JA, Hietaniemi V, Korhonen HJ, Ryhänen EL. Effect of processing and storage on the stability of flax seeds lignan added to bakery products. J Agri Food Chem 2006 Jan II;54(I):48-53. DOI: 10.1021/jf0507590.

13. Chandra MO, Raj JA, Dogra TD, Rajvanshi $A C$, Raina $A N$. Determination of median lethal dose of triazophos with DMSO in Wistar rats. Asian J Pharm Clin Res 20|4;7(4):64-7.

14. Moneim AEA, Dkhil MA, AlQuraishy S. The protective effect of flax seeds oil on lead acetateinduced renal toxicity in rats. J $\mathrm{Hazard}$ Mater 20I I Oct 30;194:250-5. DOI: 10.1016/ j.jhazmat.2011.07.097.

15. Sawant SH, Bodhankar SL. Flax lignan concentrate reverses alterations in blood pressure, left ventricular functions, lipid profile and antioxidant status in DOCA-salt induced renal hypertension in rats. Ren Fail 2016 Mar I5;38(3):4 I I-23. DOI: $10.3109 / 0886022 \times .2015$. II 36895.

16. Suvarna K, Layton C, Bancroft JD, editors. Theory and practice of histological techniques. $8^{\text {th }}$ Edition, 2018 . Elsevier, UK. DOI: 10.1016/C2015-0-00143-5.

17. Myers RB, Fredenburgh JL, Grizzle WE: 2008, Carbohydrates. In: Bancroft JD and Gamble M. $6^{\text {th }}$ ed. Theory and practice of histological techniques. UK: Churchill Livingstone, pp. 168-171.

18. Sharma D, Sangha GK. Triazophos induced oxidative stress and histomorphological changes in liver and kidney of female albino rats. Pestic Biochem Physiol 2014 Mar I; I 10:7I80. DOI: 10.1016/j.pestbp. 2014 . 03.003.

19. Rahman SA, Sattar DA. Effect of different concentration of Super Cyren pesticide on some physiological and histological traits of mice after different periods of oral administration. Iraqi J Sci 2018 Jan 8;58(4C):229I-300.

20. Ogborn MR, Nitschmann E, Weiler H, 
Leswick D, Bankovic-Calic N. Flax seeds ameliorates interstitial nephritis in rat polycystic kidney disease. Kidney Int 1999 Feb I; 55(2):417-23. DOI: $10.1046 / j .1523-1755.1999$. 00287.x.

21. Abdollahi M, Ranjbar A, Shadnia S,
Nikfar S, Rezaiee A. Pesticides and oxidative stress: a review. Med Sci Monit 2004 Jun; I (6):RA I I -7.

22. Mohineesh, Raj J, Rajvanshi AC, Dogra TD, Raina A. Effect of acute exposure of triazophos on oxidative stress and histopathological alterations in liver, kidney and brain of Wistar rats. Indian JExp Biol 20I4 Aug;52(8):8|4-9.

23. Rathod GB, Parmar P, Rathod S, Parikh A. Hazards of free radicals in various aspects of health-a review. J Forensic Toxicol Pharmacol 2014;3(2): I-7. DOI: $10.4172 / 2325-9841.1000119$.

\section{AUTHORS' CONTRIBUTIONS}

Following authors have made substantial contributions to the manuscript as under:

LS: Conception and study design, acquisition, analysis and interpretation of data, drafting the manuscript, review, final approval of the version to be published.

FF: Conception and study design, critical review, final approval of the version to be published.

MQM \& SH: Analysis and interpretation of data, drafting the manuscript, final approval of the version to be published.

RH \& MI: Acquisition, analysis and interpretation of data, drafting the manuscript, final approval of the version to be published.

Authors agree to be accountable for all aspects of the work in ensuring that questions related to the accuracy or integrity of any part of the work are appropriately investigated and resolved.

\begin{tabular}{|c|}
\hline CONFLICT OF INTEREST \\
Authors declared no conflict of interest \\
GRANT SUPPORT AND FINANCIAL DISCLOSURE \\
NIL
\end{tabular}

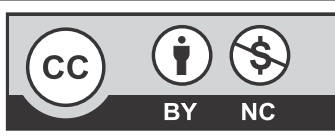

This is an Open Access article distributed under the terms of the Creative Commons Attribution-Non Commercial 2.0 Generic License.

KMUJ web address: www.kmuj.kmu.edu.pk Email address: kmuj@kmu.edu.pk 